Int. J. Electrochem. Sci., 15(2020) $8823-8836$

International Journal of

ELECTROCHEMICAL

SCIENCE

$\underline{\text { www.electrochemsci.org }}$

Short Communication

\title{
Electrolytic Polishing of Nitinol Based Cardiovascular Stent in NaCl-Ethylene Glycol-Ethanol-Water Electrolyte
}

\author{
Yongqi Wang, Xiuting Wei , Zhiyong Li, Xiaoyu Sun, Hanqing Liu, Xuemin Jing, Zhikang Gong \\ Shandong University of Technology, School of Mechanical Engineering, 266 xincun west road, \\ 255049, Zibo, China \\ *E-mail: wxt@sdut.edu.cn
}

doi: $10.20964 / 2020.09 .01$

Received: 6 April 2020 / Accepted: 10 June 2020 / Published: 10 August 2020

\begin{abstract}
Nitinol (nickel titanium alloy) is well-known as one of the best biocompatible alloys because of its excellent performance. One of the main factors affecting the performance of nitinol cardiovascular stent is their unique surface properties. To improve the surface integrity of these stents, this paper presented an electrolytic polishing method that added ethanol of different concentrations into a glycol - sodium chloride electrolyte to find the optimal electrolyte composition. This paper also investigated the change in surface chemical composition. By plotting the voltage-current density curve and the time-current density curve at various anhydrous ethanol concentrations, the optimal polishing voltage and anhydrous ethanol concentration were determined to be 16 volts and $30 \%$, respectively. According to the timecurrent density curve, the optimal polishing time was determined to be $20 \mathrm{~min}$, when obtaining the minimum surface roughness (Ra1.837 nm). Furthermore, the surface composition and formation mechanism of the stent after electrolytic polishing were analysed by XPS.
\end{abstract}

Keywords: Nitinol; Cardiovascular stent; Electrolytic polishing; Roughness; XPS

\section{FULL TEXT}

(C) 2020 The Authors. Published by ESG (www.electrochemsci.org). This article is an open access article distributed under the terms and conditions of the Creative Commons Attribution license (http://creativecommons.org/licenses/by/4.0/). 